\title{
Sobrevivência e resistência na Paris ocupada
}

Guilherme Ribeiro

$\mathbf{N}$ ASCIDO no Brasil, filho de britânicos e correspondente cultural europeu do New York Times em Paris desde 1989, o jornalista Alan Riding decidiu escrever sobre um tema caríssimo aos franceses: a ocupação nazista. E o fez sob um ângulo original: o da vida cultural. Dança, pintura, escultura, literatura, poesia, cinema e moda são passados em revista durante aquele que foi, certamente, o período mais traumático da história da França no século XX. Não se quer esquecer a Guerra de 1914, bien sîr. A questão é que a ocupação vem acompanhada de uma forte carga simbólica, presente ainda hoje em várias ruas de Paris sob a forma de placas homenageando soldados heroicos mortos em batalha e crianças judias deportadas para os campos de extermínio. Sim, tais placas também existem em menção à Primeira Guerra Mundial - mas não é a mesma coisa.

O livro de Riding foi tecido em uma narrativa direta, simples, quase objetiva, algo facilitado pela excelente tradução realizada por Celso Nogueira e Rejane Rubino. Não se trata de um texto acadêmico recheado de referências bibliográficas, notas de rodapé e pausas analíticas - o que, por conseguinte, confere um tom descritivo demais à obra. De todo modo, ele consegue resgatar a dimensão humana, cotidiana, por assim dizer, da ocupação. Talvez sua condição de estrangeiro o tenha permitido tocar em pontos assaz delicados, algo que um francês teria muitas dificuldades em fazê-lo. ${ }^{1}$ No limite, uma das questões suscitadas por ele é a seguinte: como garantir a sobrevivência material durante a ocu- pação? Receber salário dos alemães seria algo moralmente condenável, mesmo em uma situação extrema como essa? Seria sinônimo de colaboracionismo?

Claro está que Riding não desconsidera a polarização entre resistentes e colaboracionistas, mas sua argumentação caminha no sentido de tornar tal fronteira mais rarefeita. Ele parece minimizar o papel da resistência - o que pode desagradar a muitos, diga-se (p.12). Nem tudo era resistência, indica Riding. O cinema e o teatro (bastante frequentados por alemães, cabe ressaltar) nunca viveram época tão auspiciosa quanto no decorrer da ocupação (p.245). Divertir-se vendo um filme ou assistindo a uma peça era tão somente forma de distração, uma tentativa de fazer passar o tempo em uma época tão sombria.

Igualmente, sua perspectiva estrangeira faz que ele assuma uma postura que, se não é de neutralidade - posto que esta não existe em Ciências Humanas, inútil esclarecer -, também não é a de um compromisso político explícito. Assim sendo, é sem maiores delongas que Riding aponta a adesão da maioria dos franceses ao marechal Pétain quando da instalação do Regime de Vichy, visto pelo próprio Pétain como a possibilidade de erguer uma Revolução Nacional à luz de valores simples e tradicionais como trabalho, familia e pátria. Mera grandiloquência militar ou pura esquizofrenia em tempos de guerra?

$\mathrm{Na}$ mesma trilha de não possuir ligação ideológica com este ou aquele grupo, é muito interessante acompanhar as investigações do autor no período que 
precede a ocupação, quando expõe a escalada do antissemitismo na França desde o caso Dreyfus, passando pelas pressões exercidas sobre o presidente judeu Léon Blum nos anos 1930 até a formulação do Estatuto Judaico no ano de 1940. Portanto, o apoio de uma fração de escritores e de intelectuais ao encalço aos judeus e, consequentemente, ao nazismo, não surge entre 1940 e 1944, mas sim integra um processo histórico que imputava aos judeus uma série de problemas vividos pela França e pela Europa entre o final do XIX e as primeiras décadas do século XX. Nas palavras do autor: “o Estatuto Judaico já mostrava a disposição do governo francês em adotar medidas antissemitas por sua própria iniciativa, sem que houvesse pressão dos alemães. De forma ainda mais vergonhosa, ele indicava também que a Alemanha podia contar com o apoio de Vichy na perseguição aos judeus" (p.80).

Alguns leitores mais severos atestarão que Riding dedicou-se em demasia à cegueira alemã para com os judeus. $\mathrm{O}$ que não seria de todo incorreto, já que, nos onze primeiros capítulos (o livro tem dezessete), essa é uma forte impressão. Todavia, é preciso destacar seu esforço de tentar esboçar o estado da arte do mundo artístico-cultural entre 1940-1944. Uma abordagem panorâmica, poder-se-ia dizer? É provável que sim, o que não invalida os méritos do presente livro. Ele mostra, por exemplo, o profundo e real interesse - incluindo o financeiro de alemães e de franceses para com as artes. Somos informados que, antes da tomada de Paris pelos nazistas, o Louvre é esvaziado, e suas principais obras são escondidas em castelos território afora. Ao saber de um comboio partindo para a Alemanha repleto de obras de arte saqueadas da França (algo que

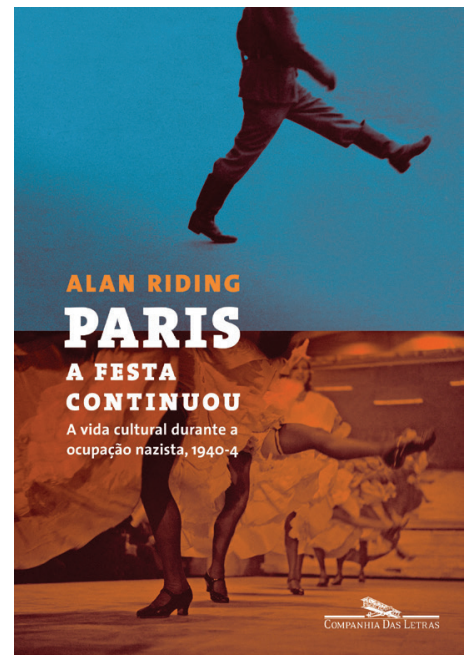

\section{RIDING, A. Paris, a festa continuou:}

a vida cultural durante a ocupação nazista,

1940-4. Trad. do inglês Celso Nogueira e Rejane Rubino. São Paulo:

Companhia das Letras, 2012. 446p.

não era consenso entre os próprios alemães, cabe destacar), a rede clandestina faz chegar tal informação à Resistência, a fim de que esta não explodisse a linha férrea e, consequentemente, os tesouros artísticos neles contidos (p.202).

Outro caso curioso e comovente: inspirados pela revista Poésie '40, que divulgava poemas de prisioneiros de guerra franceses, estes últimos acabaram por criar uma publicação mensal dedicada ao tema dentro do próprio campo de prisão. ${ }^{2} \mathrm{Em}$ 1943, aquela revista dedicaria, na íntegra, uma de suas edições aos poètes prisonniers (p.318). E o que dizer da presença de alemães na estreia de Entre quatro paredes, a segunda peça de Sartre durante a ocupação e a menos de duas semanas da chegada dos aliados à Normandia? Tal peça fora aprovada pela Propaganda Staffel, espécie de Departamento de Imprensa e Propaganda (DIP) nazista (p.258). 
O fato é que a sinistra perspectiva intelectual do III Reich guardava clara atração pela influência artística e cultural francesa, ao mesmo tempo que pretendia superá-la. Assim, tomar Paris de assalto e o território do Hexágono como um todo eram passos cruciais, porém não o suficiente, diante de tais ambições. Afinal, conforme atestara um dos censores da Propaganda Staffel, para que França e Alemanha pudessem se entender era mister que a cultura daquele país "deixasse de ser tão inconveniente" (p.70). Nesse raciocínio, nem mesmo a moda passaria incólume, pois a pretensão germânica era assumir o posto de Paris como principal centro de alta costura. "A moda parisiense deve passar por Berlim antes que uma mulher de bom gosto possa usá-la", declarou o próprio Goebbels (p.130).

Em um plano mais amplo, ainda segundo Goebels, "O resultado da nossa luta vitoriosa será o fim da supremacia cultural da França, na Europa e no resto do mundo. Depois de assegurarmos o controle de Paris - o centro da propaganda cultural francesa -, estaremos em condições de desferir-lhe um golpe definitivo. Toda forma de auxílio ou de tolerância à propaganda cultural francesa será considerada crime contra a nação" (p.69).

O livro possui inúmeros detalhes e uma profusão de nomes impossíveis de serem abordados em uma resenha. Contudo, aquele que se dispor a lê-lo e possuir de antemão alguns conhecimentos sobre o ambiente intelectual francês encontrará elementos interessantes, tais como a participação do Musée de l'Homme na Resistência; a reabertura das Éditions Gallimard, que tinha fama de optar por autores de esquerda, pelo nazista francês Drieu La Rochelle; a con- cessão de entradas gratuitas para os alemães no Louvre; a proibição de executar a Marselhesa na área controlada pela Alemanha; o apoio de Gertrude Stein a Pétain; o fascínio de Hitler pela Ópera de Paris; a apropriação do cinema pelo nacionalismo de Vichy; o envolvimento de Coco Chanel com os nazistas...

Enfim, foram tempos em que o $b u$ mano perdeu qualquer valor. "Refugiados em seu próprio país", atesta Riding ao recordar uma ocasião em que Michel Fancini, errante pelo sul da França e morto de fome, pede um copo d'água em uma fazenda (p.60). Cobraram-lhe dois francos... Cartas anônimas de franceses denunciavam judeus ou, simplesmente, desafetos de bairro... Que dizer do suicídio de Walter Benjamin? Do fuzilamento de Marc Bloch? Quantos talentos foram perdidos por conta da neurose nazista?

Talvez o maior mérito de Paris, a festa continuou tenha sido o de, ao recuperar com coragem o drama da ocupação, a atuação dos colaboracionistas e o massacre aos judeus, fazer que jamais nos esqueçamos a atração de parte da população para com regimes autoritários, bem como a dificuldade em lidarmos com diferenças étnicas, religiosas, sexuais. É um livro que serve de alerta, uma precaução para que saibamos defender, a todo custo, a democracia e a liberdade de expressão. Por incrível que pareça, elas estão sempre sendo ameaçadas. ${ }^{3}$

\section{Notas}

1 Aproveitando-se também da condição de estrangeiro, nos anos 1990 o historiador Tony Judt investigou os motivos pelos quais intelectuais de esquerda, entre 1944 e 1956 (ou seja, no período imediatamente posterior ao estudado por $\mathrm{Ri}$ - 
ding), aderiram de forma acrítica ao comunismo soviético. O livro de Judt pode, guardadas as devidas proporções, ser lido como uma espécie de continuação ao de Riding. Ambos abordam vários aspectos em comum. Ver Tony Judt, Passado imperfeito: um olhar crítico sobre a intelectualidade francesa no pós-guerra, Rio de Janeiro, Nova Fronteira, 2007 [1992].

2 Tal situação fez-nos lembrar do historiador francês Fernand Braudel que, feito prisioneiro do exército alemão entre junho de 1940 e maio de 1945, redigiu sua célebre tese La Méditerranée et le monde méditerranéen à l'époque de Philippe II. Defendida na Sorbonne em 1947 e publicada em 1949, é tida como um dos principais livros de história do século XX por sua abordagem inovadora no tocante à concepção de tempo. No cativeiro, Braudel profere palestras e chega a ser "reitor" de uma "universidade". Sobre esse tema, consulte: Erato Paris, La genèse intellectuelle de l'oeuvre de Fernand Braudel: La Méditerranée et le Monde Méditerranéen à l'époque de Philippe II (1923-1947). Athènes: Institut de Recherches Néohelleniques/FNRS, 1999.

3 A esse respeito, ver Tzvetan Todorov, Os inimigos intimos da democracia. Tradução: Joana Angélica d'Ávila Melo. São Paulo: Companhia das Letras, 2012.

Guilherme Ribeiro é professor no Departamento de Geociências da Universidade Federal Rural do Rio de Janeiro.

@ - geofilos@ig.com.br 